UDC: 821.163.41.09-4 Andrić I.

DOI: https://doi.org/10.18485/beoiber.2021.5.1.3

\author{
Krinka Vidaković Petrov ${ }^{1}$ \\ Instituto de literatura y arte \\ Serbia
}

\title{
ANDRIĆ Y GOYA
}

\section{Resumen}

El escritor yugoslavo Ivo Andrić pasó más de dos años en Madrid (1928-1930) en el cargo de vicecónsul de la Legación diplomática de Yugoslavia en España. Su experiencia de España se manifiesta en algunas de sus obras. Temas y motivos españoles que aparecen en ellas muestran tres aspectos. Uno de ellos trata del pintor español Francisco Goya. Andrić tuvo la oportunidad de conocer bien las obras de Goya gracias a una exposición extraordinaria organizada en el Museo del Prado a propósito del centenario de su muerte (1928). Goya aparece en dos obras de Andrić: «Goya» (ensayo biográfico, 1929) y «Conversación con Goya» (relato, 1935).

El estudio de estas dos obras abarca la consideración de varias cuestiones: diferencias de género entre ensayo y relato (lo documental opuesto a lo ficcional), la interpretación de obras de Goya (especialmente «Los caprichos», «Los desastres de la guerra» y los dibujos) y su poética, la divergencia y convergencia entre ensayos sobre Goya escritos por autores yugoslavos contemporáneos (Miroslav Krleža y Oto Bihalji Merin).

El análisis se centra especialmente en «Conversación con Goya», un relato excepcional sobre la creación de Goya como personaje literario, su transformación de figura histórica en artista paradigmático (el paso de la biografía a la filosofía del arte), la construcción (verbal) del retrato, el uso de la epifanía como metáfora y recurso narrativo, el uso del monólogo interior, la construcción de las dos dimensiones narrativas (la mimética opuesta a la ficcional), la analogía con El retrato de un artista adolescente de James Joyce, la interacción entre «realidad» y ficción, y, finalmente, la discreta perspectiva autoirónica que Andrić entreteje en esta narrativa extraordinaria.

Palabras clave: Ivo Andrić, Francisco Goya, ensayo biográfico, relato, epifanía como metáfora y recurso narrativo.

\footnotetext{
${ }^{1}$ krinkavidakovic@yahoo.com
} 


\section{ANDRIĆ AND GOYA}

\section{Summary}

The Yugoslav writer Ivo Andrić spent over two years in Madrid (1928-1930), where he served as viceconsul of the Yugoslav Diplomatic Legation in Spain. His experience of Spain is expressed in some of his works. Spanish themes and motifs appearing in them feature three aspects, one of them associated with the Spanish painter Francisco Goya.

Andric had the opportunity to get well acquainted with the works of Francisco Goya thanks to an extraordinary exhibition of the painter's works at the Prado Museum on occasion of the centennial of his death (1928). Goya appears in two of Andrić's works: "Goya" (a biographical essay, 1929) and "Conversation with Goya" (a fictional story, 1935).

The study of these two works involves consideration of various issues: generic differences between essay and story (documentary versus fictional), interpretation of Goya's works (especially The Caprices, The Disasters of War, and drawings) and his poetics, divergence and convergence with essays on Goya written by other contemporary Yugoslav authors (M. Krleža and O. Bihalji Merin).

The analysis is especially focused on "Conversation with Goya", an exceptional story about the creation of Goya as a literary character, his transformation from historical figure to paradigm of the Artist (shift from biography to philosophy of art), the construction of a (verbal) portrait, the use of epiphany as a metaphor and a narrative resource, the use of interior monologue, the construction of two narrative dimensions (mimetic versus fictional), the analogy with the Portrait of an Artist as a Young Man by J. Joyce, the interaction between "reality" and fiction, and last but not least - the discrete auto-ironic perspective Andrić has woven into this extraordinary narrative.

Key words: Ivo Andrić, Francisco Goya, biographical essay, short story, fiction in art, epiphany as metaphor and narrative technique.

\section{Tres aspectos del tema Andrić y España}

Ivo Andrić fue uno de los más destacados escritores yugoslavos. ${ }^{2}$ Como vicecónsul de la Legación del Reino de los Serbios, Croatas y Eslovenos para España y Portugal residió en Madrid desde abril 1928 hasta inicios de agosto 1930, cuando se trasladó a Bruselas. El tema de España aparece en tres de sus obras: el ensayo «Goya» (1929), el cuaderno de viaje «La realidad española y los primeros pasos en ella» (1934) y el relato «Conversación con Goya» (1935).

El tema de la relación de Andrić con España, y la manera en la que se manifiesta en sus obras, permaneció intacto durante muchos años. Estando en Madrid en 1986,

2 Ivo Andrić (1892-1975) nació en la villa Bosnia de Višegrad, vivió en Sarajevo, Zagreb y Belgrado. Estudió en Zagreb, Viena, Cracovia y Graz, donde consiguió su doctorado en historia en 1924. También residió en varios países donde desempeñó cargos diplomáticos en los años veinte y treinta: Rumanía, España, Bélgica, Suiza, y Alemania, donde fue embajador. Fue el único escritor yugoslavo que recibió el Premio Nobel (en 1961 por su novela Un puente en el Drina).

BEOIBERÍSTICA Vol. V / Número 1 (2021) | 43-58 
participé en las Jornadas Culturales Eslavas de la Universidad Complutense de Madrid celebrada en febrero de ese año con una ponencia titulada «Ivo Andrić y España», la que se publicó en Cuadernos Hispanoamericanos en 1989. Lo menciono por varias razones. Primero, porque marca el inicio de la serbística en España en la época posfranquista y porque fue el primer trabajo publicado sobre el tema de Andrić y España. ${ }^{3}$ Además, fue una manera de contribuir al homenaje a Andrić a propósito del aniversario de su estancia en España. ${ }^{4}$ Lo menciono también porque en ese artículo constaté que el tema de Andrić y España tenía tres aspectos.

Su primer aspecto es la relación de Andrić con el mundo de los sefardíes de Bosnia. Durante los años de su infancia y juventud en Travnik, Andrić entabló una amistad con Kalmi Baruh. Los dos hicieron sus doctorados en las universidades de Austria. Baruh luego fue el iniciador de los estudios sefardíes y padre de los estudios hispánicos en Yugoslavia (Vidaković Petrov 2016), mientras que Andrić emprendió su carrera diplomática y literaria como uno de los más destacados escritores yugoslavos en la época de entreguerras. Pero el aspecto sefardí, a pesar de ser un asunto muy interesante que he abordado en mis investigaciones posteriores, no es tema de interés en este momento. Sería suficiente señalar que Andrić conoció un aspecto de España por mediación de los sefardíes y su memoria cultural de España, una memoria filtrada por las experiencias históricas de la comunidad judeo-española de Bosnia.

El segundo aspecto es el que se basa en el contacto directo de Andrić con la realidad española durante su estancia en el país. Se trata de experiencias vividas y captadas de manera individual y personal. Son experiencias cotidianas, comentarios sobre Madrid, observaciones de las costumbres españolas o monumentos históricos y culturales, apuntes de algunas canciones populares o expresiones idiomáticas, escritos en uno de sus cuadernos (Đorđević Mironja 2017). Además, Andrić era un ávido lector, así que en sus textos aparecen también indicios de sus lecturas de escritores españoles. La nueva imagen de España que surgió de su experiencia directa y lecturas literarias españolas se manifiesta en su cuaderno de viaje «La realidad española y los primeros pasos en ella» (Andrić 1963c).

\footnotetext{
${ }^{3}$ F. J. Juez Gálvez escribe lo siguiente en «Para la historia de la serbística española»: «No obstante, durante los primeros años de esa Filología Eslava in fieri encontramos simbólica presencia de los estudios serbocroatas por medio de las ponencias de sendas profesoras belgradenses en las dos primeras ediciones de las Jornadas Culturales Eslavas de la UCM, a saber (citamos literalmente, según los programas impresos correspondientes) "Doctora Krinka Vidakovic-Petrov, profesora del Instituto de Literatura, Belgrado: Ivo Andrić y España" (19-II-1986) y "Doctora L. Samurovic, Jefe de Cátedra de Español, Universidad de Belgrado: Vuc Stefanovic Karadic, Reformador de la lengua serbocroata" (26-III-1987)» (Juez Gálvez 2020: 422)

${ }^{4}$ En 1987 las autoridades municipales de Madrid colocaron una placa conmemorativa dedicada a Ivo Andrić en el edificio que había sido su residencia en la Calle Velázquez 27.
} 
En este marco aparece un nuevo tema relacionado con el contacto directo de Andrić con las obras de Goya. Es un tema aparte que nos interesa en este momento. Se manifiesta en dos obras de Andrić: el ensayo «Goya» y el relato «Conversación con Goya». Conviene acercarse a los dos textos a la vez porque donde acaba el ensayo empieza el relato. El tema de Goya pasa de un género a otro, abriendo una serie de cuestiones interesantísimas desde el punto de vista de los estudios literarios.

\section{El ensayo biográfico}

Andrić llegó a Madrid en abril de 1928, justo cuando se inauguraba la celebración del centenario de la muerte de Goya. Su ensayo sobre Goya, publicado en 1929, empieza con una referencia a este acontecimiento cultural.

El primer contacto directo de Andrić con la cultura española se efectuó a través de las obras excepcionales de Goya. Y parece que todo lo demás que Andrić seguro que vio en el Museo del Prado se desvanecía frente a la fuerza artística de los lienzos, grabados y dibujos de Goya, muchos de estos últimos presentados al público por la primera vez.

El mismo Andrić resaltó la impresión que le dejaron las obras de Goya cuando en una entrevista comentó que la exposición duró seis meses, que él iba «a verla cada o casi cada semana» y que fue allí, en la galería del Prado, «donde surgió mí deseo de escribir un ensayo sobre Goya» (Jandrić 1977: 28). El ensayo «Goya» fue el resultado directo de esos repetidos diálogos imaginados con la obra de Goya, mientras que «La conversación con Goya» se plasmó gradualmente a partir de los ecos que seguían resonando en su memoria varios años después de la exposición, cuando Andrić ya se había marchado de España. Así lo sugiere la conclusión de su ensayo: «Goya le impresiona, asombra, horroriza y entusiasma. Y usted se va, viaja por el mundo y pasa por otros museos, pero jamás podrá olvidar a Goya» (Andrić 1963a: 105-106).

Después de esta introducción, el ensayo sigue como una narración que integra tres pautas: la biografía de Goya, la historia de su obra y los comentarios de Andrić.

Andrić presenta los datos de la vida pública y privada de Goya que uno podría encontrar en cualquiera de las varias biografías de Goya que circulaban durante la exposición conmemorativa en el Prado. La narración es cronológica, como suele ser en los ensayos biográficos. Andrić, al igual que otros biógrafos de Goya, subraya el cambio radical que dividió la vida del pintor en dos períodos muy distintos. En el primero, el joven Goya es «un español tal y como lo ha creado Dios», que expresa su visión individual de la realidad, manifestando una misteriosa fantasía y un «infinito amor por las formas y movimientos de la vida española que es una vida de doble intensidad» (Andrić 1963a: 108). Sigue la historia de su vínculo con la corte, la serie de retratos de la familia real y otros miembros de la élite social, la historia de su relación con la Duquesa de Alba y los retratos de las dos majas, cuyo cuerpo perfecto y sumamente sensual contrasta con su 
mirada «mineral». Entonces ocurre una ruptura: la enfermedad de Goya y la sordera que caracterizan la segunda etapa de su vida. Justo cuando sus éxitos culminan, escribe Andrić, empieza «un descenso a la oscura mitad de la vida y obra de Goya que [...] produjo obras de gran valor, sin las cuales Goya no ocuparía tan alto y apartado lugar entre los pintores españoles y europeos» (Andrić 1963a: 111-112). En esta segunda etapa Goya hizo los cuatro álbumes de grabados - Los Caprichos, Los Disparates (Proverbios), Los desastres de la guerra y La Tauromaquia - y un gran número de dibujos, la mayoría de ellos desconocidos durante su vida.

La atención de Andrić se centra a continuación en estas obras. Cuando escribe sobre ellas, Andrić ya no es un ensayista que presenta datos factográficos, sino un artista que responde e interpreta las obras de Goya. Andrić nota en estas obras la mezcla de apariciones nocturnas, producidas por un espíritu en agonía, con caricaturas sociales de afilada ironía y sarcasmo. Es como si Goya estuviera desnudando la realidad, quitándole las máscaras, resaltando faltas humanas, pasiones incontrolables, pecados escondidos y toda clase de monstruosidades psicológicas y morales, incluyendo la brutalidad deshumanizadora de la guerra.

En estos segmentos Andrić escribe como un artista fascinado con las obras de otro. Andrić resalta la relación complementaria entre lo visual y lo verbal, citando los «títulos» que acompañan los grabados y dibujos de Goya. Son inscripciones en forma de preguntas, comentarios, consejos, críticas «llenas de ironía, desdeño o compasión». Andrić comenta que «cuando los títulos de ciertos dibujos se conectan, parecen un diario filosóficosentimental» cuya ironía tiende a tapar «la impotente amargura del artista o su vana compasión» (Andrić 1963a: 119). Lo mismo han sugerido historiadores de arte posteriores, subrayando que Goya con estos «títulos» llevaba un diálogo con sus creaciones ficticias. ${ }^{5}$ El diálogo entre el pintor y sus creaciones es complementario con lo que Andrić, a propósito de Los desastres de la guerra, entiende por «el diálogo interior» de Goya:

¿Por qué? escribe Goya en el pie de una escena donde tres soldados ahorcan a un cautivo en una salvajada. El viejo sordo, enfermo y solitario tenía tiempo para reflexionar sobre la pregunta que se había planteado a sí mismo. Entonces, como a continuación de ese sufrido diálogo interior en el cual una pregunta eclipsaba la siguiente, escribe bajo una escena aún más horrorosa de bestialidades de guerra: No se puede saber por qué (Andrić 1963a: 119).

\footnotetext{
5 «Another singular feature of Goya's drawings is that they usually have a caption, text or inscription related to the contents of the drawing and this caption reveals much of the artist's personality and his state of mind when each drawing was conceived (...) Goya seems to converse with his creatures; he advises them, reproaches them, questions them as if he had entered into a relationship with the characters born of his pen and brush» (Lafuente Ferrari 1980: 30-31).
} 
Andrić contextualiza los grabados y dibujos escribiendo sobre los acontecimientos históricos que influyeron en la vida de Goya, ante todo la ocupación francesa, los conflictos sociales y políticos, el comportamiento del rey y la corte, las faltas humanas como son las injusticias, pecados, supersticiones y prejuicios. Resumiendo su impresión de las obras de Goya de su segunda época, Andrić cita dos versos de Les Fleurs du mal de Charles Baudlaire: "Voilà le noir tableau qu'un un rève nocturne / Je vis se dérouler sous mon oil clairvoyant». (Baudelaire apud Andrić 1963a: 114). El nihilismo de Goya, escribe Andrić, halló una expresión algo «naive» en un dibujo donde se ve la mano de un esqueleto que desde la tumba ofrece un mensaje del otro mundo - un papelito en el cual está escrita la palabra «Nada».

Los párrafos finales del ensayo cuentan los últimos años de Goya en Burdeos y su muerte. Así concluye el ensayo que manifiesta, por un lado, el entusiasmo de Andrić por Goya, experimentado en una exposición extraordinaria en Madrid, pero, por otro, una ambición modesta del autor que ni siquiera quería firmar este texto cuando se publicó en la revista Srpski književni glasnik en 1929. El propósito de Andrić era el de presentar a Goya al público yugoslavo sin otras ambiciones. ${ }^{6}$ Es evidente la profunda impresión dejada por la obra de Goya, pero no hay indicación de que cinco años más tarde Goya, y especialmente sus diálogos con sus creaciones y su conversación confesional interior reaparecerán como inspiración del relato «Conversación con Goya».

Ésta última obra de Andrić (1935) sugiere varios temas de interés para el investigador: la génesis del cuento, el paso de un género a otro (del ensayo al relato), la estructura narrativa, la epifanía como metáfora y recurso narrativo, la relación entre realidad y ficción, también entre autor real y autor implícito, etc.

Antes de visitar algunos de estos temas conviene contextualizar el ensayo de Andrić e iluminar su relación con otros dos autores yugoslavos que también escribieron ensayos sobre Goya: Miroslav Krleža y Oto Bihalji Merin.

\section{Krleža, Andrić y Bihalji Merin}

Miroslav Krleža (1893-1981) publicó su ensayo «Francisco José Goya y Lucientes» en 1926, tres años antes que Andrić. Su ensayo salió en la revista Obzor de Zagreb.

\footnotetext{
${ }^{6}$ El ensayo apareció en Srpski književni glasnik (El heraldo literario serbio), una de las más importantes revistas yugoslavas de ese tiempo. Sin embargo, Andrić no atribuía demasiada importancia a este texto, lo que comprueba su decisión de publicarlo bajo un pseudónimo (R.R). Pocas noticias de la cultura española llegaban a las revistas yugoslavas de entreguerras. Aparte de clásicos como Cervantes y escritores de la Edad de oro, los autores españoles más traducidos en esa época fueron Vicente Blasco Ibáñez y Miguel de Unamuno. El ensayo de Andrić despertó el interés del público yugoslavo por Goya.
} 
Posteriormente fue revisado y reimprimido varias veces tanto antes de la Segunda Guerra Mundial como después (Krleža 1926, 1927, 1932, 1948, 1977).

En este ensayo Krleža cuenta que había imaginado un proyecto que llamó «pentalogía épica». Su intención era la de escribir cinco dramas dedicados cada uno a los cinco personajes monumentales de la historia y cultura humana. Los cinco escogidos eran Jesús Cristo, Miguel Ángel, Cristóbal Colón, Emanuel Kant y Goya. Entre ellos figuran dos pintores, Miguel Ángel y Goya, lo que indica la importancia que Krleža atribuía a artistas, especialmente pintores. Sin embargo, su plan se materializó sólo parcialmente:

Cristo, Miguel Ángel y Colón se inflaban y dispersaban como las nubes. Kant se quedó como una idea en el cuartel de Federico el Grande (un jacobino que en las largas noches de invierno conversa con sí mismo en monólogos infinitamente largos), mientras que Francisco José de Goya y Lucientes sigue rondándome como una vieja herida (Krleža 1977: $65)$.

El proyecto de Krleža era épico. Los cinco personajes aparecían en la visión de Krleža como protagonistas de la lucha perenne por cuidar la civilización y hacerla avanzar. Krleža, el intelectual comunista par excellence, subrayaba la influencia de factores históricos y sociales que producían la necesidad de cambios revolucionarios en todos los aspectos - sociales, políticos, culturales, estéticos. Sus héroes, por lo tanto, aparecían como grandes revolucionarios. Por eso no sorprende que Krleža dedicara su drama Cristóbal Colón (1924) a Lenin. Aunque posteriormente rescindida, la dedicación sugería analogías entre los dos «revolucionarios», uno con el estatus públicamente establecido (Colón), el otro controversial en Yugoslavia, donde el partido comunista estaba bajo prohibición desde 1920.

Krleža no escribió el drama protagonizado por Goya. Escribió un ensayo con elementos metapoéticos y confesionales. El ensayo es un eco de la visión dramática de la vida de Goya imaginada para la «pentalogía épica». Krleža dedica gran parte de su ensayo a las circunstancias históricas en las cuales transcurría la vida de Goya, sus experiencias personales, su estatus social y cultural, haciendo hincapié en el cambio que ocurrió en su vejez:

Tenía justo ochenta años cuando, como Tolstoy, harto de mentiras, estupideces y pecados humanos, dejó la corte de Madrid, huyó al otro lado de la frontera y falleció en la emigración (...) Esa huida de la realidad de un viejo octogenario sordo, esa última línea vertical antes del final, es un motivo simbólico, y en esa línea audaz que lleva directamente a la muerte se encuentra la magia de un acontecimiento dramático que ejercería fascinación durante siglos. (Krleža 1977: 64) 
Krleža presenta la vida de Goya como un drama, integrando en su ensayo biográfico elementos de su propia obra dramática que no llegó a escribir. Insiste en la analogía con el gran escritor ruso en esa «línea audaz que lleva directamente a la muerte» como recurso dramático («motivo simbólico»). Esto explica el dramatismo que permea el discurso descriptivo del ensayo.

Este se centra en el acontecimiento culminante del drama biográfico, que Krleža describe como una «huida de la realidad». Sin embargo, no se trata de una «huida» sino del paso de una realidad exterior a otra interior. Entre todas las obras de Goya, Krleža destaca la trilogía de grabados - Los caprichos, La tauromaquia y Los desastres de la guerra (omitiendo Los disparates). Subrayamos que Krleža los define como «una profunda conversación confesional con uno mismo» (Krleža 1977: 66) o sea un diálogo interior confesional.

A Krleža le gustaba pensar en contextos comparativos. Así como trazó la analogía entre Goya y Tolstoy en un segmento de su ensayo, en otro comparó la obra de Goya con El sueño de una noche de verano de Shakespeare y el Fausto de Goethe, comentando que Goya no se parece al «scherzo» del primero sino a una «visión infernal faustiana» (Krleža 1977: 68).

Con un estilo barroco y muchas referencias históricas y culturales, Krleža presentó a Goya como un héroe cultural comparable a los otros cuatro personajes de su «pentalogía» imaginaria. La imagen de Goya que aparece en su ensayo tiende a ser más poética que discursiva a pesar de la gran cantidad de datos históricos y biográficos. Es una imagen épica e hiperbolizada con un fuerte matiz social y ético que al mismo tiempo ilumina su mundo interior, la escena en la que tiene lugar el drama que «ejercería fascinación durante siglos».

Otro autor yugoslavo que escribió sobre Goya fue Oto Bihalji Merin (1904-1993). Aunque fue también escritor, es más conocido como historiador del arte. Krleža y Bihalji Merin fueron dos de los más destacados representantes de la inteligencia de la izquierda política de Yugoslavia. ${ }^{7}$ Estuvo en España en 1932 durante la Segunda República y fue testigo de la defensa de la República en la Guerra Civil en 1936, estando con las Brigadas internacionales como periodista. Conoció las obras de Goya durante su primera estancia en España, pero escribió sobre este pintor por primera vez en su libro Spanien Zwischen Tod Und Geburt, publicado primero en alemán (Zurich,1937), después en inglés (Nueva York,1938) y finalmente en serbio (Belgrado, 1946).

Cuando en 1961 la editorial Matica srpska de Novi Sad preparaba la publicación de «Goya» y «Conversación con Goya», Bihalji Merin fue encargado de escribir la

\footnotetext{
${ }^{7}$ El conocido escritor y periodista Arthur Koestler, autor de la novela El cero y el infinito (Darkness at Noon), calificó a Bihalji Merin como «personaje legendario en París y Berlín en los años treinta» (Ivanji 2004). En esa época Bihalji Merin jugaba un papel importante en la red político-cultural comunista de Europa.
} 
«Introducción». La edición de ambos textos en el mismo volumen sugirió su interpretación conjunta. El primero que adoptó este enfoque fue Bihalji Merin, a quien también debemos las primeras interpretaciones de dos cuestiones que este enfoque sugiere. La primera trata del problema de género. Bihalji Merin califica «Goya» como «una reseña histórico-crítica» (ensayo), mientras que «La conversación con Goya» es «prosa poética» (obra literaria ficcional) (Bihalji Merin 1961: 6). Esta cuestión fue interpretada de diferentes maneras en los textos críticos posteriores. Bihalji Merin abrió la segunda cuestión con el siguiente comentario: «No obstante, cuando Andrić escribía sobre el método creativo de Goya, a mí me parece que expresaba al mismo tiempo su propio Credo [artístico]» (Bihalji Merin 1961: 7). Se trata de la relación entre autor, narrador y personaje.

Bihalji Merin alabó el ensayo de Andrić, escribió mucho más sobre «Conversación con Goya», mientras que varios segmentos de su «Introducción» presentan sus propios comentarios sobre la obra de Goya complementando los de Andrić.

Bihalji Merin vio las obras de Goya en Madrid en 1932 y fue testigo de su evacuación del Prado durante la Guerra Civil. La experiencia viva de las obras de Goya resultó en una fascinación profesional y personal con ellas. «El recorrido del Prado fue para mí como un camino por las fases de la vida de Goya, su desarrollo artístico y subjetivo.» Dos libros extraordinarios dedicados a Goya son prueba de esa fascinación. Ambos serían publicados 50 años después del primer contacto de Bihalji Merin con Goya: Goya, Caprichos. Their Hidden Truth (Bihalji Merin 1981a) y Goya Then and Now. Paintings. Portraits. Frescoes (Bihalji Merin 1981b). ${ }^{8}$ A diferencia de Krleža y Andrić, Bihalji Merin interpretó las obras de Goya desde la perspectiva de un historiador del arte, especialmente uno interesado en señalar la relevancia de Goya en contextos artísticos del siglo XX. A diferencia de Krleža, quien resaltaba lo dramático en el personaje de Goya y su vida, Bihalji Merin se centra en el análisis de su obra y los modelos estéticos que las obras de Goya proyectan hacia épocas posteriores. ${ }^{9}$

Al mismo tiempo, Bihalji Merin subraya dos características del ensayo de Andrić. Resalta que su inspiración para el ensayo surgió «de lo visto y vivido de paso» en los encuentros del escritor con las obras de Goya en la exposición conmemorativa en el Museo del Prado. Y también su manera de presentarlo: un tono «reservado» que «ya en esa época fue característico de Andrić» (Bihalji Merin 1961: 5). En cuanto a Krleža, Bihalji Merin no hace más que mencionar su «ensayo interesante» (Bihalji Merin 1961: 6).

\footnotetext{
8 Publicados primero en alemán, después en inglés, pero nunca en serbio.

9 Un ejemplo es el modelo creado por Goya en «El 3 de mayo», la obra inspirada por la resistencia de los madrileños a la ocupación francesa. Sus versiones aparecen en obras de autores de los siglos XIX y XX como son Édouard Manet («Ejecución del Emperador Maximiliano»), Petar Dobrović («La matanza en Šabac 1914»), Picasso («La matanza en Korea»), así como en obras que tratan del Holocausto.
} 
En la actualidad, ambos textos de Andrić son bastante conocidos, los de Bihalji Merin mucho menos, mientras que el ensayo de Krleža ha caído en el olvido. ${ }^{10}$

\section{La epifanía como metáfora y recurso narrativo}

Aunque Andrić tampoco menciona a Krleža, la comparación de los dos ensayos revela relaciones intertextuales que sugieren algunos puntos de divergencia $o$ convergencia.

El primero es la referencia de Andrić a lo «faustiano» en la obra de Goya. Mientras que Krleža califica la obra de Goya como una visión «faustiana», Andrić opina que «no hay nada...faustiano en ella». Lo que sí hay, opina Andrić, es nihilismo. En la visión de Goya no hay dualismo - los dos mundos que predica la religión (uno de aquí y otro del más allá) o la ética (uno de dios y otro del diablo) - sino monismo. La realidad es una y la vida del hombre en ella es «un martirio sin consolación celestial». Este mundo único es dramatizado mediante una contradicción interior, pero eso no implica su dualidad. Esto podría ser una referencia al ensayo de Krleža por divergencia.

Krleža comenta que Goya le perseguía como «una herida vieja». Andrić escribe que dondequiera que uno vaya después de haber visto las obras de Goya, no podrá olvidar a éste. Es la misma idea expresada de dos modos: discurso metafórico (Krleža) y descriptivo (Andrić). Este detalle señala una diferencia general entre los dos estilos: el de Krleža, a pesar de la densa factografía, tiende a ser más poético/dramático que el de Andrić, escrito en tono reservado, como ya observó Bihalji Merin. ${ }^{11}$ Lo poético del ensayo de Krleža puede ser un eco de la intención frustrada del autor de escribir un drama sobre Goya como parte de su «pentalogía épica». En el caso de Andrić, se nota una separación nítida entre los dos tipos textos sobre Goya - el ensayo como comentario de la vida y obra de Goya (documental) y el relato como narración literaria (ficcional).

A pesar de esta diferencia, hay un segundo punto de contacto entre los ensayos de Krleža y Andrić. Aunque Krleža describe el personaje de Goya en términos dramáticos y épicos congruentes con la idea básica de su «pentalogía», el Goya que después de todo sigue volviendo como «una herida» es muy diferente:

10 T. Brajović comenta un artículo de Ranko Risojević (1968: 401-402) diciendo que es «el único texto conocido hasta ahora dedicado a la comparación de lo que los dos escritores escribieron sobre el mismo personaje» (Brajović 2012: 81-114, 86-87). Aunque hay un artículo más sobre el mismo tema (v. Brlenić-Vujić 1988: 10), Brajović tiene razón en señalar que el ensayo de Krleža suscitó poco interés entre lectores y críticos. ${ }^{11}$ Aunque Tihomir Brajović (Brajović 2012) interpreta la diferencia general entre los dos ensayos sobre Goya en el marco de la relación elaborada por Nikola Milošević (Milošević 1976), su análisis es mucho más extenso y ofrece ideas nuevas e interesantes. Desgraciadamente, no podemos comentarlas en este artículo debido a restricciones de espacio. 
Goya se me presenta a menudo como una tormenta y a menudo ese infeliz viejo me habla con claridad, así que oigo cada palabra y entiendo todos sus pensamientos, incluso los más recluidos, y siento maravillosamente cada trazo de su punzón...Hoy en día Goya es para mí la voz sosegada y serena de un viejo, listo para su último viaje al exilio...Todo acaba en el mol ${ }^{12}$ de un alba callada, como cuando la candela se va apagando y las primeras manchas del día aparecen en el horizonte" (Krleža 1977: 65-66).

Esta es la imagen de Goya que aparece en el relato de Andrić, que a diferencia de Krleža, transformó el Goya histórico en un personaje ficcional, o sea literario.

Además, Andrić construyó la estructura narrativa alrededor de un personaje literario que se presenta como retrato de Goya, siendo la parte más importante del relato el monólogo interior o confesional del personaje. En un sentido, lo que hizo Andrić es análogo a lo que hizo Joyce, pero en vez de ofrecer el retrato de un artista joven en una novela (Portrait of an Artist as a Young Man), Andrić presenta el retrato de un artista viejo (Goya) en un relato corto. Volveremos a esa analogía más tarde.

En este momento conviene señalar que el Goya de Andrić es muy parecido al Goya que sigue volviendo a Krleža en sus pensamientos: es viejo e infeliz, habla con voz serena y sosegada, sus palabras se oyen igual que sus pensamientos, es como una aparición que se desvanece cuando se apaga la luz interior (de la candela) y aparece la luz exterior (del alba). En esta descripción de Krleža, igual que en el relato de Andrić, Goya es un fantasma análogo a personajes que habitan la imaginación, el sueño, la memoria y la ficción literaria.

En «Conversación con Goya» es un personaje creado por el narrador del relato, mientras que el acto de creación está presentado como una epifanía.

La epifanía es una metáfora de la creación de un personaje literario (análogo al retrato que hace un pintor), pero en este caso concreto es al mismo tiempo el acontecimiento crucial de la fábula. La epifanía produce una nueva situación: la presencia de Goya (muerto hace más de un siglo) en el mundo del narrador (contemporáneo a Andrić). Es la intrusión del pasado en el presente, de la ficción en la realidad, de lo intangible en el mundo material. Y ocurre en una taberna modesta que recuerda a la taberna bíblica. Mientras que aquella dejó pasar la oportunidad de ser el lugar de la epifanía, la del arrabal de Burdeos lo fue.

La epifanía, en este caso, supone la existencia de dos dimensiones paralelas. En un momento extraordinario/epifánico se efectúa el contacto entre ellos. Este facilita la

\footnotetext{
12 Semitono en música.
} 
manifestación de algo perteneciente a una dimensión en la dimensión del otro. ${ }^{13}$ En el relato de Andrić, la epifanía se refiere a la manifestación del personaje literario/ficcional en lo que el lector percibe como la realidad material/mundana del narrador (una taberna en un arrabal de Burdeos) que Andrić ya había presentado como un sitio de encuentro de lo posible y lo imposible, el pasado y el presente, los muertos y los vivos.

Aunque en el relato aparecen dos voces primarias, una del personaje-narrador y otra del personaje designado como Goya, estas se manifiestan en dos mundos paralelos. La sugerencia de Andrić de que se trata de un diálogo o sea una conversación con Goya es sólo una ilusión que el mismo narrador disipa: «Así continuamos la conversación que en realidad fue un monólogo de Goya sobre él mismo, el arte, las cosas generales del destino humano» (Andrić 1963b: 123). Es un monólogo interior y el único que puede oír a Goya y al narrador es el lector que está fuera de la ficción literaria.

\section{La construcción de la dimensión real}

La dimensión realista, o sea mimética, se construye a través del personaje-narrador. Lo que sabemos de este personaje es sólo lo que el lector puede deducir de su narración que es homodiegética. La narración de este personaje anónimo consta de informes, descripciones (de paisajes, objetos, gente, acontecimientos, situaciones), impresiones y meditaciones. Su informe empieza con «...me quedaba una veintena de kilómetros hasta Burdeos». La oración siguiente contiene descripción y meditación: «...noté al lado derecho de la carretera grandes postes [...] seguí conduciendo pensando todo el tiempo en la similitud entre las catedrales esbeltas y envejecidas y estas torres de acero». Paseando por uno de los arrabales de Burdeos el narrador llega al sitio donde tendrá lugar el acontecimiento principal: «... ya cansado me senté en frente de una taberna [...] cerca de la taberna, en un prado...estaban armando una tienda de circo [...] estas pequeñas tabernas en los arrabales...son más o menos iguales en todos los sitios y no cambian con los tiempos y las modas». La descripción cede a sus pensamientos y su imaginación: «Llevando en mis ojos la imagen de estas catedrales modernas, en las que en cada momento ocurre un milagro, me parecía que mi pensamiento y mi imaginación se desarrollaban con más facilidad y rapidez resucitando tiempos pasados y gente fallecida». Así, la narración (preepifánica) prepara al lector para el milagro, pero no el de la tecnología moderna que los produce cada día, sino un milagro excepcional: la aparición de Goya que empieza su monólogo.

${ }^{13}$ En el cristianismo, es la manifestación de la dimensión sacra y espiritual en la realidad mundana y material. La epifanía es la festividad religiosa que se celebra el día 6 de enero, en que los cristianos conmemoran la adoración de Jesús por los Reyes Magos y su aparición y manifestación al mundo.

BEOIBERÍSTICA Vol. V / Número 1 (2021) | 43-58 
El tiempo de la epifanía coincide con un personaje, una voz y un monólogo del otro mundo. Es la manifestación de la «realidad» interna de la obra artística (una ficción) en la realidad externa del creador. Cuando se apagan la luz y los ruidos, termina la epifanía y Goya sale de la escena (la taberna). En ese momento se reanuda la narración (postepifánica): el personaje-narrador vuelve a su hotel, al día siguiente espera la puesta del sol, se va a la taberna en aquel arrabal, espera a Goya, pero él no viene, pide papel y pluma para escribir el monólogo de Goya, sale de la taberna, busca a Goya en la multitud de gente que había venido al circo, no lo encuentra. "Tenía que dejar de buscar lo que no se puede encontrar», dice el narrador, concluyendo su narración: "Al día siguiente, temprano por la mañana, me marché de Burdeos para siempre» (Andrić 1963b: 147).

Su narración imita un cuaderno de viaje con la típica convención de comienzo/ entrada y fin/salida. Describe un paisaje contemporáneo (postes telegráficos, coche), un ambiente modesto (un arrabal de Burdeos) y un sitio genérico (una taberna local) situada entre dos extremos espaciales representados por la iglesia (lo celestial) y el circo (lo mundano). La narración empieza proyectando una imagen realista del ambiente, pero poco a poco algunos elementos asumen significado simbólico.

\section{La construcción de la dimensión ficcional}

En este caso, la epifanía no ocurre como un relámpago, sino como una presencia casi imperceptible y frágil, tanto que el narrador se queda mudo, temiendo que «el viejo» pudiera desaparecer «como hacen las apariencias» (Andrić 1963b: 125).

Mientras la narración del personaje anónimo es inaudible para Goya, la escucha el lector, que nota que el narrador interrumpe el monólogo de Goya sólo tres veces con comentarios que describen el aspecto de Goya y su manera de hablar.

En el primer comentario aparecen dos detalles que iluminan la construcción de la dimensión ficcional. El primero es la descripción de la voz de Goya: «...el viejo hablaba con una voz turbia de pecho, que sólo de vez en cuando subía a la garganta como una llama que no se dejaba atenuar ni esconder» (Andrić 1963b: 125). No es voz, sino llama que asciende de una oscura profundidad (¿del alma, del subconsciente, del misterio?). La sinestesia fusiona los sentidos. Sugiere una versión atenuada de la imagen de la lava ascendiendo de la profundidad de la tierra hacia la boca del volcán para salir fuera.

El segundo detalle es la descripción de la mano de Goya. Conviene realizar una digresión volviendo al monólogo de Goya. Entre los temas elaborados está la teoría del retrato:

...en cada cuadro siempre hay un solo sitio que produce la ilusión de la realidad, la del observador. Es el único objeto importante y crucial, como la firma en un pagaré. Ese objeto 
pueden ser los ojos o la mano o simplemente un botón de metal iluminado de una manera especial (Andrić 1963b: 138).

La mano de Goya, que el personaje-narrador describe, es su instrumento de creación, pero aún más importante es ese detalle crucial en el retrato de Goya. Su función es la de mantener la ilusión de realidad (verosimilitud) de la ficción artística/literaria. Todo lo demás en el retrato de Goya es borroso: Goya está escondido bajo el sombrero y la capa, la cara casi no se ve, hay una niebla alrededor de sus ojos. Lo único que se presenta claramente es su mano, que evidentemente no es de este mundo:

Una mano asombrosa, como una raíz-amuleto mágica, nudosa, gris, fuerte y seca como un túmulo en el desierto. Esa mano vive, pero su vida es la de una piedra. En ella no hay sangre ni jugo ninguno, es de una materia que desconocemos. No es una mano para estrechar ni acariciar, ni para recibir ni dar. ¿Mirándola, uno se pregunta con miedo si esto es algo que podía hacerse de una mano humana? (Andrić 1963b: 124-125).

Imita una mano humana, pero no lo es. Es tenebrosa, mágica, misteriosa, de una materia desconocida, al mismo tiempo muerta y viva, se esfuma como la arena y es fuerte como la piedra. Es el símbolo de la creación y la obra de arte. Viene de «la nada», «la oscuridad de la inexistencia» que el artista rescata como trozos de vida y sueño humanos: «Nosotros [los artistas] sentimos que estamos arrebatando algo de alguien, rescatándolo de un mundo oscuro e integrándolo en otro que desconocemos, quitando de la nada y vertiéndolo en algo que no sabemos qué es» (Andrić 1963b: 126-127).

La epifanía transmite la imagen de la creación y la historia del proceso creativo representado por un pintor extraordinario, Goya, en un relato creado por un escritor extraordinario, Andrić.

\section{Conclusión: El retrato de un artista viejo}

El ensayo biográfico es un género documental, así que el retrato del personaje histórico, en este caso Goya, consta básicamente de datos biográficos. Ya hemos notado que Andrić se distancia del modelo documental del ensayo biográfico cuando interpreta los «títulos» de los grabados y dibujos a través de los cuales Goya «dialoga» con sus propias creaciones. Andrić interpreta los «títulos» como una serie que en su conjunto aparece como «un diario filosófico-sentimental». Algo parecido es el monólogo en «Conversación con Goya». En un sentido secundario es hasta cierto punto biográfico. Sin embargo, en un sentido primario es subjetivo, filosófico y poético. Es el autorretrato de un pintor particular, Goya, que es al mismo tiempo un artista paradigmático.

De allí deriva la analogía con el Retrato de un artista adolescente. La novela de Joyce tiene claros elementos autobiográficos. La epifanía que el protagonista vive a finales de la 
narración simboliza su decisión de dedicarse a la creación artística. El relato de Andrić es biográfico. Aquí la epifanía simboliza la creación artística per se expresada en el monólogo interior de un creador (Goya).

No sin ironía el lector se da cuenta de que este creador (Goya) es un personaje literario creado por otro personaje literario (el narrador anónimo), ambos creados por el autor real - Andrić.

\section{BIBLIOGRAFÍA}

Andrić, Ivo. «Goja.» Staze. Lica. Predeli. Beograd: Prosveta; Zagreb: Mladost; Sarajevo: Svjetlost; Ljubljana: Državna založba Slovenije, 1963a. 105-120. Štampano.

- . «Razgovor s Gojom.» Staze. Lica. Predeli. Beograd: Prosveta; Zagreb: Mladost; Sarajevo: Svjetlost; Ljubljana: Državna založba Slovenije, 1963b. 121-147. Štampano.

—. «Španska stvarnost i prvi koraci u njoj.» Staze. Lica. Predeli. Beograd: Prosveta; Zagreb: Mladost; Sarajevo: Svjetlost; Ljubljana: Državna založba Slovenije, 1963c. 165-170. Štampano.

Bihalji Merin, Oto. «Predgovor.» Zapisi o Goji. Ivo Andrić. Novi Sad: Matica srpska, 1961. 5-17. Štampano.

-. Goya, Caprichos. Their Hidden Truth. New York; London: Harcourt Brace Jovanovich, 1981a. Print.

-. Goya Then and Now. Paintings. Portraits. Frescoe. New York; London: Harcourt Brace Jovanovich, 1981b. Print.

Brajović, Tihomir. «Andrićev Goja u svetlu komparativnog razumevanja.» Komparativni identiteti. Beograd: Službeni glasnik, 2012. 81-114. Štampano.

Brlenić-Vujić, Branka. «Recepcija Goje u Krleže i Andrića: književna i kulturna komunikacija.» Odjek 41.23 (1988): 10. Štampano.

Đorđević Mironja, Biljana. «Ivo Andrić. Mali notes blok 1929-1930». Sveske Zadužbine Ive Andrića 34 (2017): 15-79. Štampano.

Ivanji, Andrej. «Lepi život u paklu.» Vreme, 08.01.2004. Štampano.

Jandrić, Ljubo. Sa Ivom Andrićem 1968-1975. Beograd: Srpska književna zadruga, 1977. Štampano.

Juez Gálvez, Francisco Javier. «Para la historia de la serbística española.» Srpski kao strani jezik u teoriji i praksi. Beograd: Filološki fakultet: Centar za srpski kao strani jezik, 2020. 419-428. Štampano.

Krleža, Miroslav. «Francisco José Goya y Lucientes.» Obzor, 25.II.1926. Štampano.

—. «Francisco José Goya y Lucientes.» Književna republika, 1927, IV.2. Štampano.

—. «Francisco José Goya y Lucientes.» Eseji. v. I. Zagreb: Minerva, 1932. Štampano.

-. Francisco José Goya de Lucientes. Zagreb: Nakladni zavod Hrvatske, 1948. Štampano. 
-. «Francisco José Goya y Lucientes.» Eseji II - Evropske teme. Izbor, redakcija i komentari Mate Lončar. Beograd: Sloboda, 1977. 62-70. Štampano.

Lafuente Ferrari, Enrique. Goya. Drawings. Bilbao: Silex, 1980. Print.

Milošević, Nikola. Andrić i Krleža kao antipodi. Beograd: Slovo ljubve, 1976. Štampano.

Palavestra, Predrag. Skriveni pesnik: Prilog kritičkoj biografiji Ive Andrića. Beograd: Slovo ljubve, 1981. Štampano.

Risojević, Ranko. «Goja - Andrićev i Krležin». Putevi XIV.5 (1968): 401-402. Štampano.

Vidaković Petrov, Krinka. «Kalmi Baruh y los estudios hispánicos modernos en Yugoslavia.» Estudios hispánicos en la cultura y ciencia serbia: Actas de la Primera conferencia nacional de hispanistas serbios (Facultad de Filología y Artes de Kragujevac, 28-29 noviembre 2014). Anđelka Pejović et al. (eds). Kragujevac: Facultad de Filología y artes de Kragujevac, 2016. 161-169. Impreso. 